\title{
Computer-Aided Study of Materials' Microstructure Influence on Cracks' Propagation Pattern in Brittle Anisotropic Bodies
}

\author{
Sergey Vasilevich Voronin ${ }^{1}$, Valentin Dmitrievich Yushin ${ }^{1} \&$ Galina Zakharovna Bunova ${ }^{1}$ \\ ${ }^{1}$ Samara State Aerospace University, Samara, Russia \\ Correspondence: Sergey Vasilevich Voronin, Samara State Aerospace University, Samara 443086, Russia. E-mail: \\ VORONIN@ssau.Ru
}

Received: October 26, 2014 Accepted: November 6, 2014 Online Published: December 11, 2014

doi:10.5539/mas.v9n3p51 URL: http://dx.doi.org/10.5539/mas.v9n3p51

\begin{abstract}
The purpose of the presented study is a solution of a boundary-value problem, a visualization and a study of crack propagation pattern of a plane specimen of an anisotropic brittle material by computer modeling method. As main software for the research, MSC Nastran finite-element analysis package is used. As a result of the presented study, a methodology for a creation of finite-element models of various structural constituents and specimens with consideration of material's microstructure is developed. Developed methodology is tested during the creation of finite-element model of the specimen assigned for a fracture with stress concentrators of varying forms and with a consideration of hypothetical structure, consisting of three types of crystallite with different mechanical properties. The methodology is proposed for an evaluation of kinetics and visualization of the crack growth in models of isotropic and anisotropic brittle materials. As the result of step-by-step visualization of the crack growth, animation files in AVI-format are created, which allow us to analyze the process of the material fracture. A theoretical equation is proposed for determination of the crack growth trajectory, which defines a relationship between a work needed for the crack growth and stresses in the specimen and its geometric parameters. An influence of the material on the trajectory of the crack growth is determined. Results of the presented study can serve as a tool for development of new materials with a high crack resistance due to their optimal microstructure. Developed methodologies allow you to determine desired location, size, shape of grains and their mechanical properties in microstructure of created material, without fabrication of many expensive full-size specimens.
\end{abstract}

Keywords: microstructure, finite-element analysis, crack propagation, brittle anisotropic body

\section{Introdution}

An assessment of structural materials' quality in a context of fracture mechanics becomes increasingly important during a development of new materials or regimes of thermomechanical strengthening, and criteria of fracture mechanics are becoming increasingly implemented in a design of various crucial structures, because those tests maximally model service conditions (cracks presence, appropriate environment, stress field - plane deformation, plane stress condition, etc.). A solution of problems of mechanics of main cracks' development for bodies of complex shape and complex loading conditions is difficult to imagine without use of effective computer-aided numerical methods. Finite-element method due to its versatitility became the most widely spread (Alshoaibi, A., M., et. al., 2009; Souiyah, M., et. al., 2009; Dongwoo Sohna, et. al., 2011).

Therefore, as it was mentioned above, there is a large number of fracture criteria, a selection of a criterion will be primarily determined by a specification of solved problem. The most important problem is a creation of an automated method for the determination of the crack growth trajectory in a material with maximum realism of described structure (Soon Wan Chung, et. al., 2002).

During the study of processes of structural materials' fracture and the development of new materials it is necessary to be able to visually observe a pattern of the cracks growth depending on phase and structural composition of the material (Guido Dhondt, 2012; Voronin, S.V., et. al., 2008).

A large number of researches are dedicated to the study of various structural elements, which have various stress concentrators. Generally, the material of structures is set as isotropic (Tilbrook, M. T., et. al, 2005; Ooi, E.T., et. al., 2012; Gui'e Xu, Feng Fang, Zhaoxia Li, 2009; Wen Zhong, Jiajie Hu, Jun Guo, Zibin Li \& Quyue Liu, 
2009).

A number of researches concerns the crack growth due to an influence of alternating fatigue loads (Rahman, M. M., et. al., 2009; Liwei Wu, et. al., 2014).

A literature analysis shown that there is a need to develop more advanced methods of computer modeling of a real structure, which can provide an opportunity to consider all types of materials and features of their structure. A problem that remains topical, is the problem of automation of certain types of the creation of structures' finite-element models, as most of proposed methods are labor-intensive and require high qualification from a researcher or a designer in order to be able work with finite-element based software (Dong, W, et. al., 2013).

The goal of the presented study is the solution of boundary-value problem, visualization and study of the cracks propagation patterns of the plane specimen of anisotropic brittle material by computer modeling method.

To achieve that goal it is necessary to solve following problems:

1. To develop the methodology for the creation of finite-element models of specimens, taking into account material's microstructure.

2. To conduct a computer modeling of the crack growth process in models isotropic and anisotropic elastic specimens with geometric defects of varying shape.

\section{Material and Methods}

The computer-aided studies were conducted on personal computer with dual core $2 \mathrm{GHz}$ processor and $2 \mathrm{~GB}$ RAM and using finite-element method based software - MSC Nastran for Windows. The main idea of finite element method is that any continuous value, such as temperature, pressure or displacement can be approximated by a discrete model, which is based on a variety of piecewise-continuous functions, which are defined in a finite number of sub-regions.

All above mentioned software are operating in Windows XP environment. Preparation of geometrical model, partitioning into finite elements, setting physico-mechanical properties of materials and loads was conducted in pre-, post- processor Femap 8.2. For pre-, post-processor Femap 8.2, Nastran 2005 software was used as a resolvent.

During the creation of samples scale factor was considered: according to similarity theory, in a case of scale change in 100 times differences in stress-strain state of studied specimens does not exceed $1 \%$.

Process of fracture was studied with two finite-element models with $3 \times 1.5 \times 1 \mathrm{~mm}$ size from test brittle material. One model was fully isotropic with Young modulus equal to $71000 \mathrm{MPa}$ and ultimate tensile strength $-300 \mathrm{MPa}$, and the second with three structural components having different values Young modulus $-50000 \mathrm{MPa}, 71000$ $\mathrm{MPa}$, over $80000 \mathrm{MPa}$ and ultimate tensile strength, respectively, $200 \mathrm{MPa}, 300 \mathrm{MPa}$ and $450 \mathrm{MPa}$. From both sides of specimens stress concentrators in a form of triangular cuts with the dimensions $0.1 \mathrm{~mm}$ (height) and $0.04 \mathrm{~mm}$ (base of the triangle) were placed symmetrically, relative to median longitudinal line. That pattern of stress concentrator's placement is because of an intention to avoid bending of specimens under due to external tensile forces, which value was changed in a process of numerical experiment from 0 to $200 \mathrm{MPa}$. Between stress concentrators in a stripe, where the crack is expected to grow, in order to model porosity of the specimen, defects of the specimen's geometry in the form of gaps of various shape were introduced, also in a symmetrical manner: rhombus with sizes of diagonals $0.032 \times 0.018 \mathrm{~mm}$; heptagon with sizes of diagonals approximately equal to $0.04 \mathrm{~mm}$; pentagon with sizes of side equal to $0.014 \mathrm{~mm}$ for the creation of a more complex stressed state of a model.

\section{Results}

\subsection{The Methodology of Finite-Element Model's Creation with the Consideration of Material's Microstructure}

For creation of two-dimensional model (2-D model) or three-dimensional model (3-D model) finite-element models of structural and phase components, the following methodology was developed.

1. The first step of the creation of the 2-D and 3-D finite-element models was the creation of a geometry model of studied specimens (using menu functions Geometry...). It included the creation of external borders or surfaces of the specimen and pores. Shape and size of the specimen was chosen in accordance with objectives of the study. Pores had the spherical shape. Coordinates of pores' location inside the body of the specimen were set using a random number generation software and their dimensions were set in accordance with data about a value of material's porosity and size distribution of pores. During the creation of pores under pressure, it is necessary to know the value of level of gas saturation of the material, in order to calculate pressure, which is occurring in 
pores, in accordance with that value.

2. In the second stage, properties for all structural constituents of the material (using menu functions Model $\rightarrow$ Materials...), which number is equal to the number of grains' groups and strengthening phases, with the same physical-mechanical properties.

3. Further, partitioning of previously the created model of the specimen with pores in finite elements, which shape was regulated in settings of Mesh generation (using menu functions Mesh).

4. In the fourth stage, the number and size of grains, phases and cracks were set, the centers of the listed structural constituents were assigned (Figure 1).

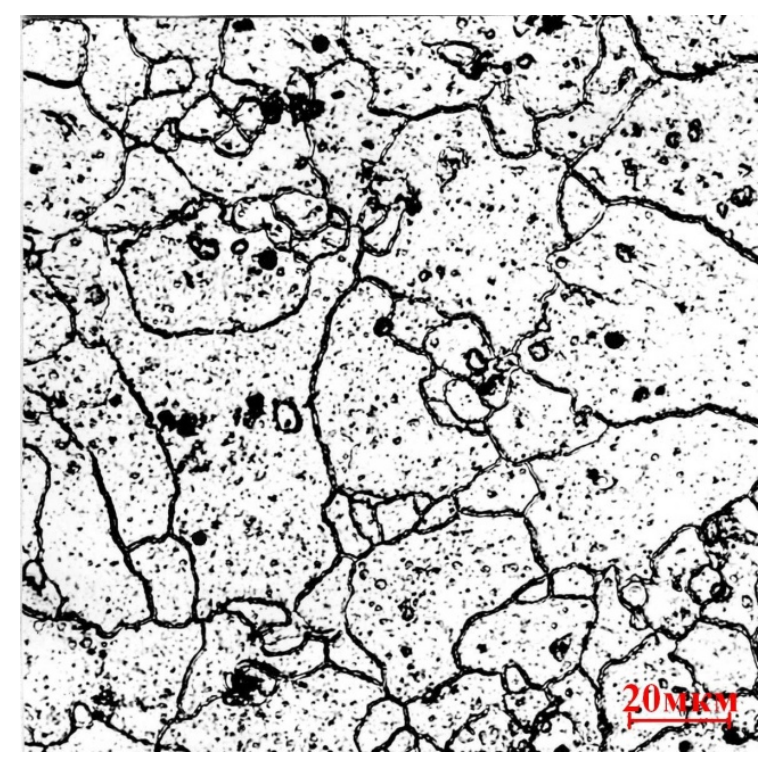

A

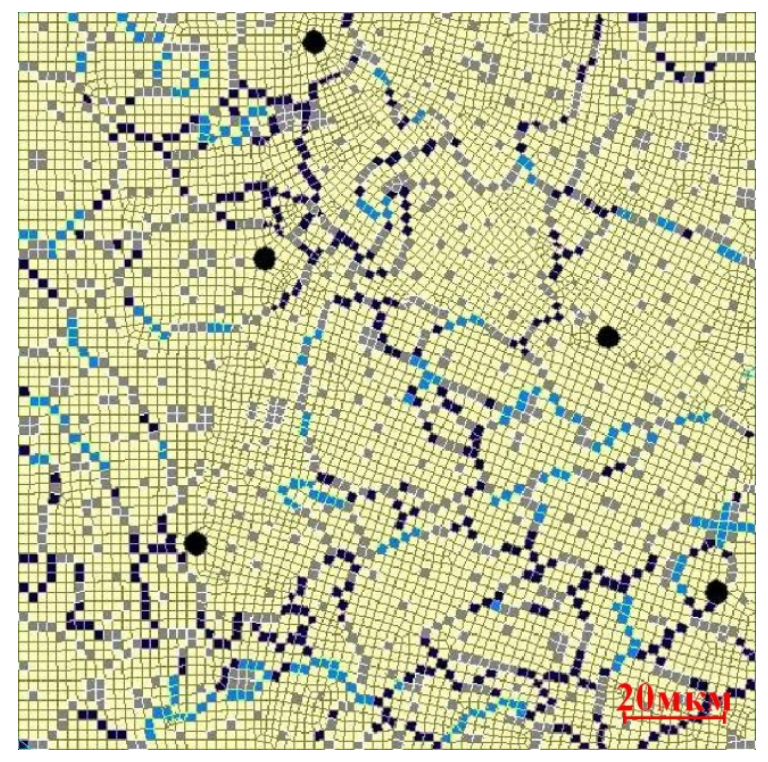

$B$

Figure 1. Microstructure of Al-6\%Mg alloy: $\mathrm{a}$ - microstructure of the studied alloy; $\mathrm{b}$ - finite-element model of alloy's structure

In order to do that, a microsection of the studied material was made (for example, $\mathrm{Al}-6 \% \mathrm{Mg}$ alloy), which was placed on microscope with a digital camera, that allowed to send an image of microstructure to a computer. The image of the microstructure was processed using the image analysis software Expert Pro 3.0, which is designed for acquisition, preparation and analysis of the raster images. Using data, received from the Image Expert Pro 3.0 software, graphs of grains' distribution by size and number were created. The graph was created for the 2-D image of a structure. In order to determine the number of structural constituents in the unit of volume, the following relationship was used: $\mathrm{N}=\mathrm{n} / \mathrm{d}_{\mathrm{cp}}$, where $\mathrm{N}$ - number of grains in $10^{-6} \mathrm{~m}^{3}, \mathrm{n}-$ number of grains in $10^{-4}$ $\mathrm{m}^{2}, \mathrm{~d}_{\text {avg }}$ - average size of a grain in a thin section's plane. Then, appropriate properties were assigned to each group, which was forming a structural constituent. Centers of structural constituents were assigned using the random number generator with implementation of adjusted data of the structural constituents' size distribution graph. Centers of listed structural constituents in the model, which was partitioned into finite elements, were independent elements. Other elements were attached to selected nodes of an element (using menu functions Group $\rightarrow$ Node $\rightarrow$ on Element...), using commands (Group $\rightarrow$ Element $\rightarrow$ using Node...) for an attachment of mesh elements. In turn, on the attached elements, new nodes can be selected to increase or change shape of structural constituents of the material. The shape and size of the structural constituents was controlled visually on the computer's screen.

\subsection{The Method of Modeling of the Crack Growth Process in Finite-Element Models of Specimens with the Consideration of Material's Structure}

The basis of developed method of visualization of the crack growth comprises two principles:

The fracture of the material occurs at the ultimate tensile strength under applied external forces in independent points of the finite-element model; 
The crack grows in a direction of minimum work's conduction during growth on distance, which is determined by finite-element's value.

The first principle determines a place of the material fracture in the finite-element models of isotropic and anisotropic specimens, and the second - the direction of the trajectory of further growth of the crack.

In order to study the pattern of the crack growth, model of the 2-D specimens were selected - isotropic (Figure 2), and another one with similar geometric sizes, but composed of three different structural constituents, which are considering anisotropy of real material's properties (Figure 3).

After the creation of the geometry model of the specimen, in order to use the MSC Nastran for Windows software, partitioning of the surface into finite elements of triangular shape with a minimum size of $1 \cdot 10-4 \div 2 \cdot 10-4 \mathrm{~m}$ was conducted. Such shape of the element is selected in order to increase the number of directions of the expected growth of the crack. The value of final elements by length of the specimen was uneven, which was related with necessity to reduce the number of finite elements for reduction of the model's analysis time.

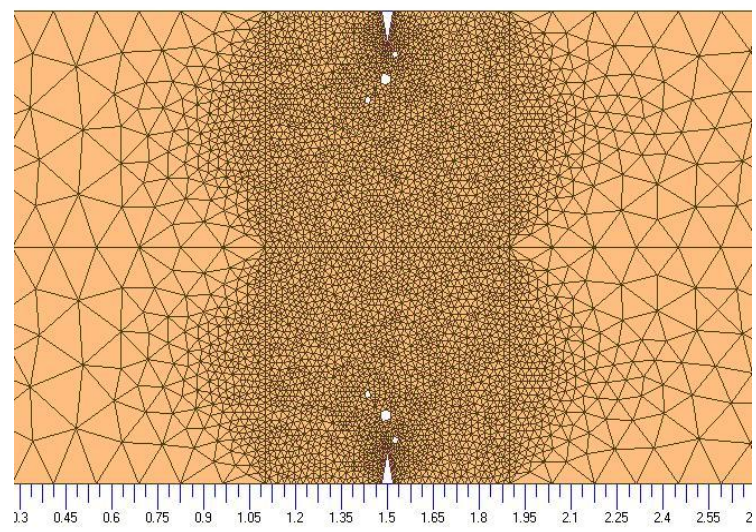

Figure 2. Overview of finite-element model of isotropic specimen

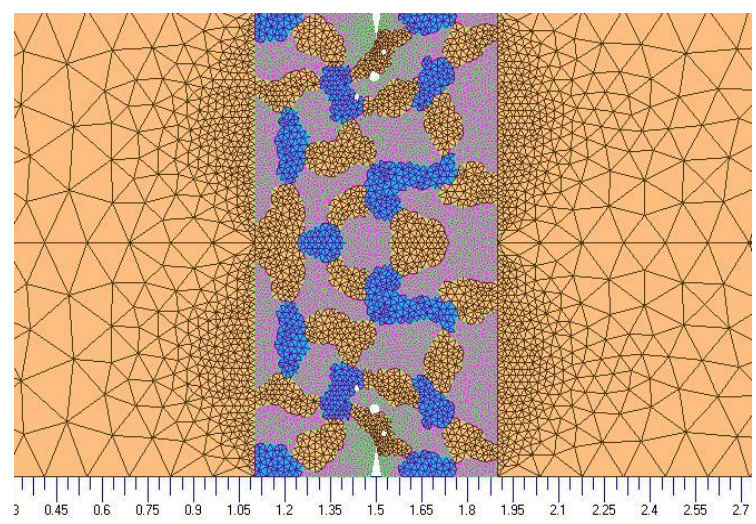

Figure 3. Overview of finite-element model of anisotropic specimen

During the study of the pattern of the crack growth, it was assumed that the crack will grow in an intermittent manner and step's value will be accepted as equal to the edge of the finite element. The assumption of an intermittent growth of the crack is based on data from literature.

In order to visualize growth of the crack with an application of external load, the following measures were taken. After achievement of the value of equivalent stress of Von Mises in an independent node of a mesh, which is equal to the ultimate tensile strength of one of structural constituents, a division in two of a node was conducted in a top of the crack. At the same time, the direction of the crack growth was determined using following values: minimal difference of stresses in the top of the crack and nodes of expected directions of the crack growth and cosine of angle between Y-axis and a line of possible displacement of the crack's top (Figure4).

On the basis of that data, work, which was spent on the crack's displacement, was calculated, using proposed 
empirical equation (1):

$$
A=\frac{\left(\sigma_{g}-\sigma_{i}\right) \times l^{2} \times t}{\cos \alpha}
$$

where A - work spent on the crack's displacement, J;

$\sigma_{\mathrm{g}}-$ stress at the top of the crack, $\mathrm{N} / \mathrm{m}^{2}$;

$\sigma_{\mathrm{i}}-$ stress in the node, in which following division in two is expected, $\mathrm{N} / \mathrm{m}^{2}$.

1 - distance between the node at the top of the crack and the node, in which following division in two is expected, $\mathrm{m}$;

$\mathrm{t}$ - thickness of the specimen, $\mathrm{m}$;

$\alpha$ - angle between Y-axis and the direction of expected the crack growth, degrees.

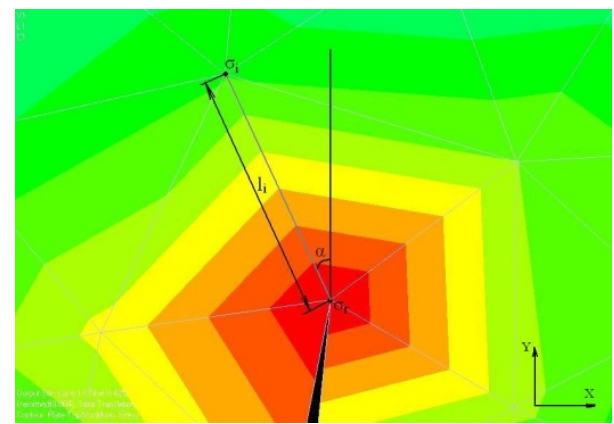

Figure 4. Parameters, which are necessary for a calculation of work during the crack growth

A sequence of step-by-step calculation of the crack growth trajectory in the finite-element model can be presented in the form of a scheme (Figure 5).

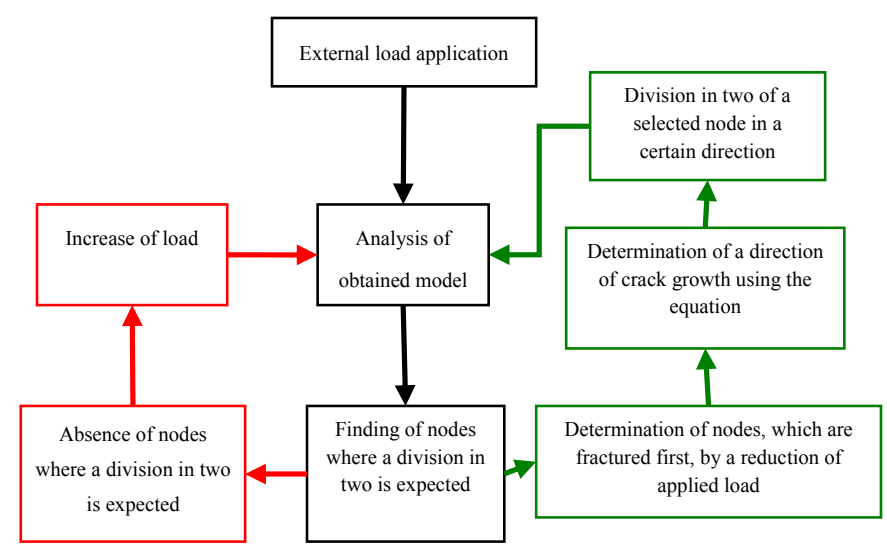

Figure 5. The algorithm for determination of the trajectory of the crack growth

\section{Discussion}

In accordance with the proposed algorithm, at the beginning of the study, a load is applied to specimens' models, after which the models are analyzed, in order to obtain images of distribution of stress and deformation along the specimen's body. Using stress values in areas of expected the crack growth, the nodes, which stresses exceed specified ultimate tensile strength for the given structural constituent, are determined. If several nodes, in which the stress exceeded the ultimate tensile strength, are found, it is necessary to reduce the load to a level, at which the number of that kind of nodes will be equal to one. Then, around those nodes all nodes are selected, which lay in the range from $0^{\circ}$ to $180^{\circ}$ relative to $\mathrm{X}$-axis, in which the direction the crack growth is possible. For all 
possible directions, the work required for the crack growth is calculated using the proposed equation. Then, the node, in which the stresses exceeded the ultimate tensile strength, is divided in two in the direction, in which it is necessary to conduct minimal work. The obtained finite-element model is analyzed, and, then, again, the nodes, in which the stresses exceeded the ultimate tensile strength, are determined. In the case of their absence, the applied load is increased.

Results of the visualization of the crack growth trajectory are presented in Figure 6-10, which use the proposed methodology of isotropic and anisotropic specimens with defects of various shape, which are introduced in order to create a complex pattern of the stress distribution.

In discussed studies, the solution of problems is presented, which pertain to the crack growth, however, materials, in which the cracks grow, are considered as isotropic bodies, without taking into account their microstructure (Zhoua, M-J, et al., 2014; Li, J., et al., 2014; Ozgur Aslan, Samuel Forest, 2009; Adelzadeh, M., et al., 2008; Khoei, A.R., et al., 2012; Tianqi Wang, Liangyu Li, Xiao Li \& Xu Yang, 2009).

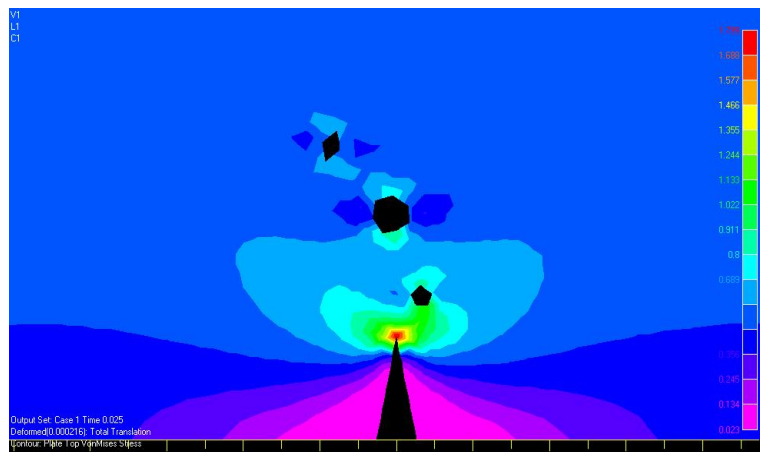

Figure 6. Stress-strain state of isotropic specimen model in step 1

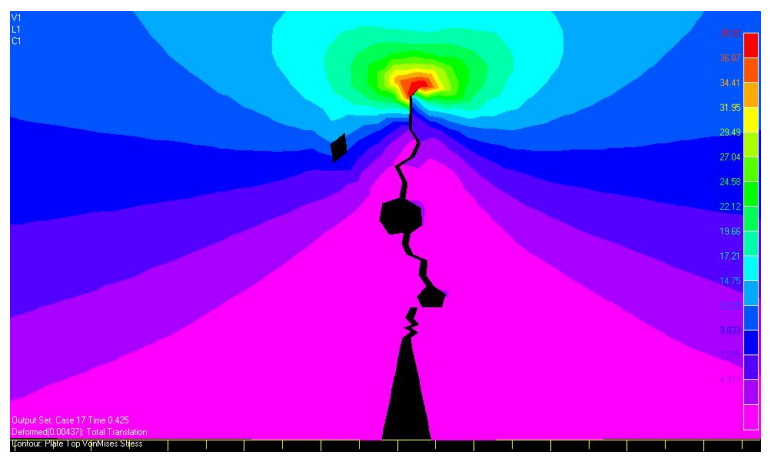

Figure 7. Stress-strain state of isotropic specimen mode 1 in step 32

The crack growth for the material with three different structural constituents and with the same defects is presented in Figure 8, 9, 10.

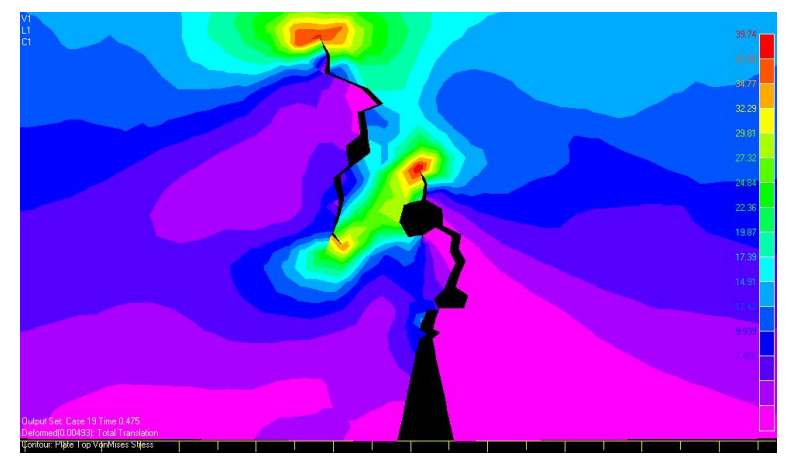

Figure 8. Stress-strain state of anisotropic specimen model in step 32 


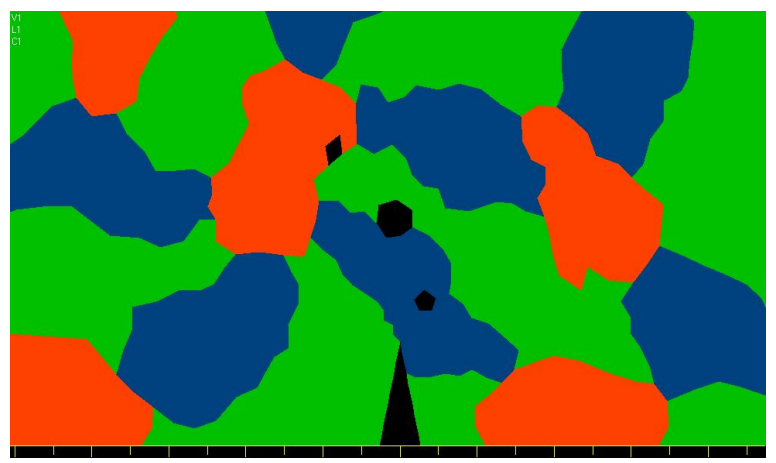

Figure 9. Initial image of anisotropic specimen's structure

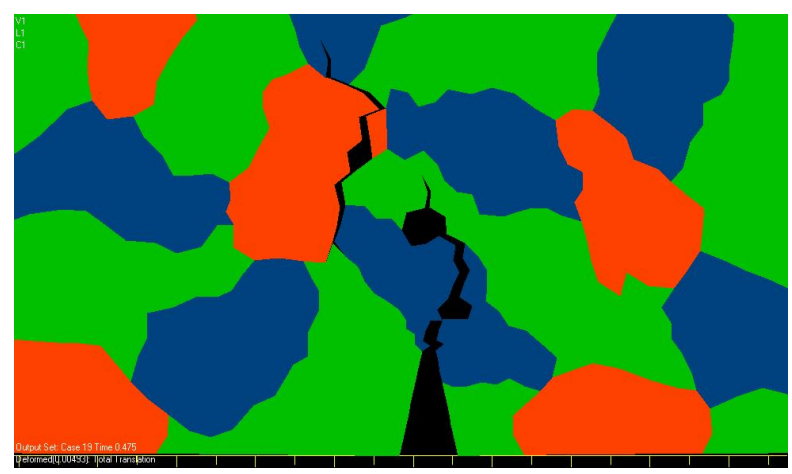

Figure 10. The trajectory of the crack growth with the image of the structure of anisotropic specimen in step 32

\section{Conclusion}

Thus, as a result of the conducted investigations, the methodology is developed, which is designed for the creation of finite-element models of various structural constituents of materials, for the computer modeling of the crack growth in models of isotropic and anisotropic elastic specimens with various shapes of defects. Also, the possibility of the visualization of the crack growth is demonstrated in the case of the fracture of elastic structural materials. As the result of step-by-step visualization of the crack growth, the animation files in AVI-format are created.

In order to increase precision of the trajectory of the crack growth with finite-element modeling, it is necessary to implement remeshing of finite elements around the tip of the crack.

\section{Acknowledgement}

This work was supported by the Ministry of education and science of the Russian Federation in the framework of the implementation of the Program of increasing the competitiveness of SSAU among the world's leading scientific and educational centers for 2013-2020.

\section{References}

Adelzadeh, M., Shodja, H. M., \& Rafii, T. H. (2008). Computational modeling of the interaction of two edge cracks, and two edge cracks interacting with a nanovoid, via an atomistic finite element method. Computational Materials Science, 42, 186-193. http://dx.doi.org/ 10.1016/j.commatsci.2007.07.012

Alshoaibi, A. M., Ariffin, A. K., \& Almaghrabi, M. N. (2009). Development of efficient finite element software of crack propagation simulation using adaptive mesh strategy. American Journal of Applied Sciences, 6(4), 661-666. http://dx.doi.org/ 10.3844/ajas.2009.661.666.

Chung, S. W., Seung, J. K., \& Jin, H. K. (2002). Finite element simulation of metal forming and in-plane crack propagation using ductile continuum damage model. Computers \& Structures, 80(23). http://dx.doi.org/ 10.1016/S0045-7949(02)00205-5

Dong, W. S., Jae, H. L., Young, S. C., Jeong, H. K., \& Seyoung, I. (2011). Finite element analysis of quasistatic crack propagation in brittle media with voids or inclusions. Journal of Computational Physics, 230(17), 
6866-6899. http://dx.doi.org/ 10.1016/j.jcp.2011.05.016

Guido, D. (2012). Application of the Finite Element Method to mixed-mode cyclic crack propagation calculations in specimens. International Journal of Fatigue, 58, 2-11. http:/dx.doi.org/ 10.1016/j.ijfatigue.2013.05.001

Khoei, A. R., Moslemi, H., \& Sharifi M. (2012). Three-dimensional cohesive fracture modeling of non-planar crack growth using adaptive FE technique. International Journal of Solids and Structures, 49(17), 2334-2348. http://dx.doi.org/ 10.1016/j.ijsolstr.2012.04.036

Li, J., Proudhon, H., Roos, A., Chiaruttini, V., \& Forest, S. (2014). Crystal plasticity finite element simulation of crack growth in single crystals. Computational Materials Science, In Press. http://dx.doi.org/10.1016/j.commatsci.2014.03.061

Liwei, W., Zhang, F., Zhong, B. S., \& Hong, B. G. (2014). Finite element analyses on three-point low-cyclic bending fatigue of 3-D braided composite materials at microstructure level. International Journal of Mechanical Sciences, 84, 41-53. http://dx.doi.org/10.1016/j.jmecsci.2014.03.036

Ooi, E. T., Song, C., Tin, L. F., \& Yang, Z. J. (2012). Automatic modelling of cohesive crack propagation in concrete using polygon scaled boundary finite elements. Engineering Fracture Mechanics, 93, 13-33. http://dx.doi.org/10.1016/j.engfracmech.2012.06.003

Ozgur, A., \& Samuel, F. (2009). Crack growth modeling in single crystals based on higher order continua. Computational Materials Science, 45(3), 756-761. http://dx.doi.org/10.1016/j.commatsci.2008.09.016

Rahman, M. M., Rosli, A. B., Noor, M. M., Sani, M. S. M., \& Julie, J. M. (2009). Effects of spot diameter and sheets thickness on fatigue life of spot welded structure based on FEA approach. American Journal of Applied Sciences, 6(1), 137-142. http://dx.doi.org/10.3844/ajas.2009.137.142.

Souiyah, M., Muchtar, A., Alshoaibi, A., \& Ariffin, A. K. (2009). Finite element analysis of the crack propagation for solid materials. American Journal of Applied Sciences, 6(7), 1396-1402. http://dx.doi.org/ 10.3844/ajassp.2009.1396.1402.

Tilbrook, M. T., Moon, R. J., \& Hoffman, M. (2005). Finite element simulations of crack propagation in functionally graded materials under flexural loading. Engineering Fracture Mechanics, 72(16), 2444-2467. http://dx.doi.org/10.1016/j.engfracmech.2005.04.001

Voronin, S. V., Yushin, V. D., \& Bunova, G. Z. (2008). Computer-aided simulation of the AMg6 alloy rolling process with allowance for its anisotropy. Russian Aeronautics (Iz VUZ), 51(4), 457-460. http://dx.doi.org/ $10.3103 / \mathrm{S} 1068799808040181$

Wang, D., Zhao, J., Zhou, Y. H., Chen, X. X., Li, A. H., \& Gong, Z. C. (2013). Extended finite element modeling of crack propagation in ceramic tool materials by considering the microstructural features. Computational Materials Science, 77, 236-244. http://dx.doi.org/10.1016/j.commatsci.2013.04.045

Wang, T. Q., Li, L. Y., Li, X., \& Yang, X. (2009). The Numerical Simulation and Control of Microstructure in Heat-affected Zone in GMAW. Modern Applied Science, 3(5). http://dx.doi.org/10.5539/mas.v3n5p162

Wen, Z., Hu, J. J., Guo, J., Li, Z. B., \& Liu, Q. Y. (2009). Study on the Growth of the Fatigue Crack under Flexural Moment. Modern Applied Science, 3(11). http://dx.doi.org/10.5539/mas.v3n11p24

Xu, G. E., Feng, F., \& Li, Z. X. (2009). Optimization of the Technology of Wire Drawing Based on Finite Element Modeling. Modern Applied Science, 3(5). http://dx.doi.org/10.5539/mas.v3n5p193

Zhou, M. J., Song, C., Bao, Y., \& Li, C. F. (2014). A quasi-static crack propagation simulation based on shape-free hybrid stress-function finite elements with simple remeshing. Computer Methods in Applied Mechanics and Engineering, 275, 159-188. http://dx.doi.org/10.1016/j.cma.2014.03.006

\section{Copyrights}

Copyright for this article is retained by the author(s), with first publication rights granted to the journal.

This is an open-access article distributed under the terms and conditions of the Creative Commons Attribution license (http://creativecommons.org/licenses/by/3.0/). 